\title{
Collaborative Governance in Poverty Alleviation in Ngada Regency, East Nusa Tenggara Province
}

\author{
Seferinus Niki ${ }^{1}$, Endang Larasati ${ }^{2}$, Sri Suwitri ${ }^{3}$, Hardi Warsono ${ }^{4}$ \\ \{larasati57@ymail.com ${ }^{2}$ \} \\ Universitas Diponegoro, Indonesia ${ }^{1,2,3,4}$
}

\begin{abstract}
This research was conducted to describe and analyze the Implementation of collaborative governance in poverty alleviation and supporting and inhibiting factors in it. Research locus in Ngada Regency, East Nusa Tenggara Province, Indonesia. This type of research is descriptive qualitative. Data collection techniques used were interviews, observation, FGD, observation and document review. Data validity is tested through data triangulation and data analysis using data condensation, data presentation and conclusion drawing. The results showed that collaborative governance in poverty alleviation in Ngada Regency, East Nusa Tenggara Province has not fully met the substantial elements of collaborative governance according to deSeve which includes network structure, commitment to a common Purpose, trust among the participants, governance, access to authority, distributive accountability/responsibility, information sharing and resource access. The dynamics of collaboration have not yet taken place in the real sense. The resource, leadership, institutional and cultural factors are the four factors that influence and inhibit collaboration. Drivers of collaboration include the need for resource sharing, leadership vision on poverty issues, recognition of potential among stakeholders. Obstacles include resource gaps, less facilitative leadership, no representative institutions and a strong culture of government dominance.
\end{abstract}

Keywords: Collaborative Governance, Poverty Reduction, Stakeholders.

\section{Introduction}

The development of public administration has brought a new nuance in terms of organizing governance called the governance paradigm [1]. The approach that highlights the role of government that characterizes the old public administration paradigm is increasingly abandoned along with the emergence of a collective awareness of the importance of the governance model that opens the space for participation of all components in public administration. Governance refers to the understanding that power is no longer solely owned or owned by the government. Governance emphasizes the implementation of the governing function jointly by the government and other components outside the government. Nongovernment institutions can play a dominant role in governance or even more than that government does not take any role "governance without government" [2].

Further implications of the application of the governance paradigm have given rise to a new concept in governance called Collaborative Governance. This concept arises as the community develops so that the government faces more complex problems. On the other hand, the government has limitations to overcome these problems so it requires collaboration with external actors. Thus, cooperation is initiated on the limitations of capacity, resources and 
networks owned by each party, so that cooperation can unite and complete various components that drive the success of achieving common goals.

Chris Ansell and Alison Gash defines Collaborative Governance as governance in which one or more public institutions directly involve non-state stakeholders in collective decision making processes that are formal, consensus-oriented, and deliberative and aim to create or implement policies public or manage programs or public assets Here Collaborative Governance is defined as the unification of public institutions and institutions of nongovernment related parties in the principle of equality for decision making and joint action, which is expected to contribute greatly to the successful handling of public problems. Although in equality, the government still plays the role of coordination, facilitation, and control [3].

In the context of handling the problem of public poverty, Collaborative Governance is interpreted as an appropriate strategy to provide a space for multi-stakeholder participation so that the handling of poverty becomes more comprehensive. The collaboration developed is expected to increase accuracy in identifying the true causes of poverty and the obstacles that accompany it so that interventions of various programs can have a significant impact on reducing poverty and improving people's welfare. In addition, collaboration can be realized if there is a synergy of roles and joint commitment from all parties to face poverty as a common enemy and together think of more appropriate ways to deal with problems. Poverty alleviation cannot produce significant results if it only relies on the role of the government. Other stakeholders outside the government need to get a place in an integrated poverty reduction scheme. Thus, awareness of the potential of stakeholder.

The still poor condition of poverty is a major challenge in efforts to reduce poverty in Indonesia from time to time. Various programs, activities and budgets continue to be launched by the government to deal with poverty. Although in general poverty reduction efforts have had an impact on reducing poverty over time, the problem of poverty is still a crucial problem. The reality that cannot be denied is the high percentage of poor people seen from various poverty indicators. In the national scope, statistics do show that there has been a decline in the percentage of poverty in Indonesia from time to time. In the period 2007-2017 there has been a decrease in the percentage of poor people as seen from the graphic presentation in figure 1.

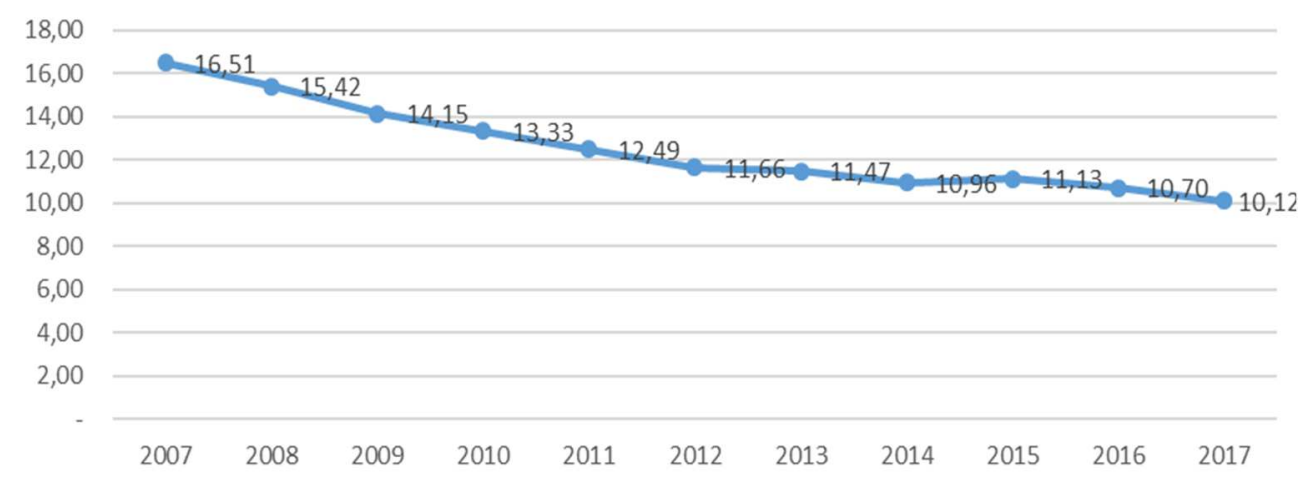

Fig. 1. Percentage of Poor Indonesians 2007-2017 (Statistics Indonesia, 2019).

From the existing graph shows in the period of 10 years (2007-2017) there has been a decline in the percentage of poor people by $6 \%$. The percentage of poor people in 2007 the percentage of poor people amounted to 16.51 continued to decrease to 10.12 in 2017. More specifically, it can also be seen in the period 2007 to 2012 there was a better downward trend 
with an average decline of $1 \%$, but the following years show a relatively slow decline. The slowing down in poverty reduction has become a contradiction because precisely at this time the government is promoting a program to accelerate poverty reduction followed by various poverty reduction programs.

Disparity between regions is indeed a serious problem with the existence of areas categorized as poverty pockets in Indonesia with a very high percentage of poor people. Regions with the highest percentage of poverty is as shown in the table below:

Table 1. The Ten Poorest Provinces in Indonesia

\begin{tabular}{ccc}
\hline Ranking & Province & Percentage of poor population \\
\hline 1 & Papua & 27,76 \\
2 & Papua Barat & 23,12 \\
3 & NTT & 21,38 \\
4 & Maluku & 18,29 \\
5 & Gorontalo & 17,14 \\
6 & Aceh & 15,92 \\
7 & Bengkulu & 15,59 \\
8 & NTB & 15,05 \\
9 & Sulawesi Tengah & 14,22 \\
10 & Sumatera Selatan & 13,10 \\
\hline
\end{tabular}

Source: Statistics Indonesia, 2017.

As one of the provinces which has a very large percentage of the poor population of $21.35 \%$ with an aggregate number of poor people of $1,150,790$ people in 2017 , East Nusa Tenggara is a province that contributes significantly to poverty in Indonesia. This percentage which is far above the national average makes poverty in NTT a heavy burden not only for NTT Province itself but also a national burden. Furthermore, if we look at the trend of decreasing poverty in the period 2007-2017, it shows conditions that are almost the same as the national downward trend with the achievement of a decrease of approximately $6 \%$. This achievement is certainly not comparable with many poverty alleviation programs launched during this period, including the Budget Program for the People Towards Prosperity (Red Wine) and the Mandiri Wine Red Village Program (DeMAM) launched by the NTT Provincial Government and a number of programs at the district/cities like East Nusa Tenggara.

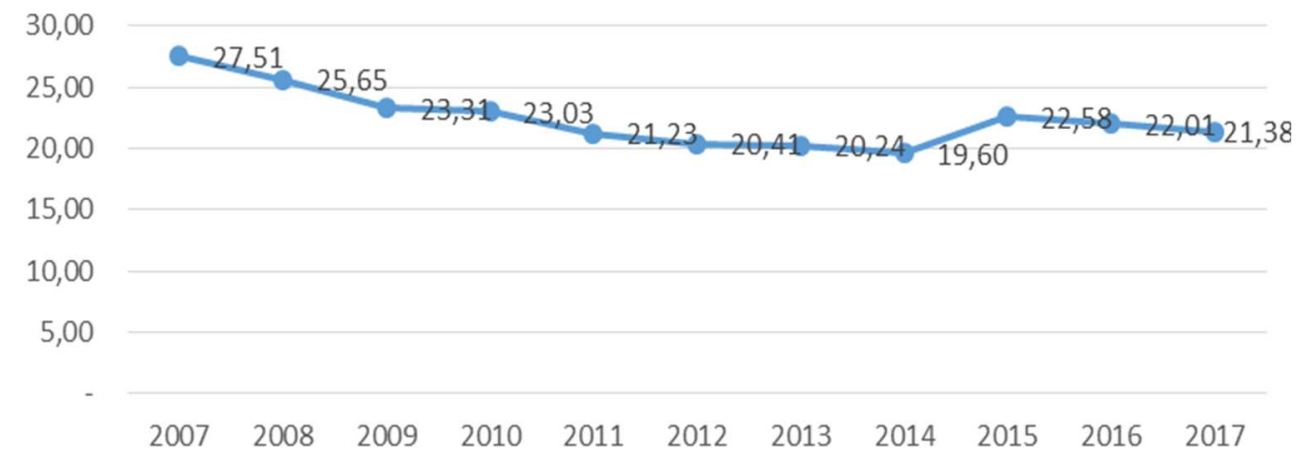

Fig. 2. Percentage of Poor Population in NTT 2007-2017 (Statistics Indonesia-NTT, 2017) 
The graph shows that there has been a decline in the percentage of poverty over time, even with a slow pace of decline. From the condition of $27.51 \%$ in 2007 to $21.38 \%$ in 2017 , it means that within 10 years it succeeded in reducing the percentage of poverty by $6.13 \%$. This achievement when compared to other provinces in Indonesia, especially the ten provinces that are categorized as the poorest in Indonesia, then NTT's achievements are actually in the slow category with a very small percentage. The province with the fastest percentage reduction in the period 2007 to 2017 is West Papua Province with the achievement of a decrease of $16.19 \%$. The percentage of poor people in East Nusa Tenggara Province is $11.21 \%$ higher than the percentage of Indonesia's poor population of $10.64 \%$. With these conditions, then in fact NTT is making a very large contribution to the problem of poverty in Indonesia. It is clear that the problem of handling poverty is not only a burden for the people of NTT itself but also a national burden from time to time that requires joint mitigation efforts.

Specifically, Ngada Regency as one of the regencies in East Nusa Tenggara Province for researchers has an interesting phenomenon for further scrutiny. On one hand, the percentage of poor people in Ngada Regency is relatively small compared to other districts in East Nusa Tenggara. In 2017 the percentage of poor people in Ngada Regency was 12.77\%, which shows the condition is far below the percentage of poor people in NTT Province which is $21,38 \%$. But on the other hand, if observed from the decrease in the percentage of poor people in the period 2010 to 2017, the percentage of poor people in Ngada Regency has actually increased. In 2007 the percentage of poor people in Ngada Regency was 12.05 percent which moved down in the following years up to 2014. However, in 2015 up to 2017 the percentage of poverty actually experienced a drastic increase and actually exceeded the initial conditions in 2010 with achievements the last year was 2017 at $12.77 \%$. With this achievement, the poverty conditions in Ngada District were in a stagnant position and even increased. Whereas in that period there were a number of programs launched by the government from various resources along with the poverty reduction acceleration program launched by the central government.

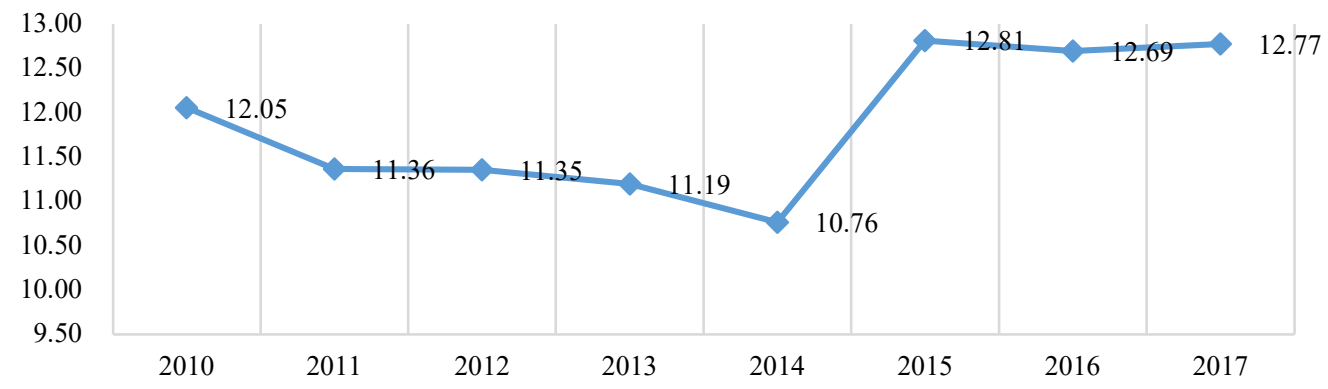

Fig. 3. Percentage of poor people in Ngada Regency in 2010-2017 (Statistics Indonesia-BPS Ngada Regency, 2018).

According to Benfiglioli, one of the principles underlying the development and implementation of poverty reduction strategies is that it must involve broad-based participation by civil society and the private sector in all operational and partnership-oriented steps [4]. From this understanding, collaborative management is an integral aspect that cannot be overlooked in poverty alleviation. Therefore, any failure to achieve the poverty reduction target must be material to confirm whether or not the handling of poverty has been carried out in a collaborative principle. Although the government has the financial strength and ability to 
design various programs and activities, if without the involvement of other components, it will not produce maximum results and can even lead to failure. Thus, a collaborative approach to poverty alleviation will actually provide maximum results that indirectly help the government carry out its constitutional task of welfare of the people.

The Process or Dynamics of Collaboration is not something that happens by itself but requires a condition that gives encouragement and provides support. Ansell and Gash [5] describe Collaborative Governance as a dialogical series of four variables namely Starting Condition, Facilitative Leadership, Institution Design and Collaborative Process [5]. The Collaboration Process consists of five stages that run in a cycle consisting of Face to Face Dialogue, Trust Building, Commitment to Process, Shared Understanding and Intermediate Outcomes. Collaboration process can occur if supported by Starting Condition, Institution Design and Facilitative Leadership. Meanwhile, in the perspective of Emerson, Nabachi and Balogh (2012), Collaborative Governance has three interrelated components. The three components include System Context, Drivers and Collaborative Dynamic[6]. Collaborative Dynamic includes three Interaction Components namely Principled Engagement, Shared Motivation and Capacity for Joint action. System context and Drivers are conditions that provide impetus for the dynamics of collaboration among stakeholders. System Context as an external condition that gave birth to the need for collaboration, while the driver as a driving force that allows the collaboration process. Collaborative Dynamic is an interaction process that consists of Principled Engagement, Shared Motivation and Capacity for Joint action.

DeSeve states that there are important items that can be used as indicators to measure the successful implementation of collaborative governance. These criteria include: (1) Networked Structure, (2) Commitment to a Common Purpose, (3) Trust Among the Participants, (4) Governance, (5) Access to Authority, (6) Distributive Accountability Responsibility, (7) Information Sharing, (8) Access to Resources [7]. While the factors that influence the collaboration process are resources, leadership, institutions and culture [5] [6] [7] The results of research on the Implementation of Collaborative Governance in Poverty Reduction in Ngada Regency show the following matters [7].

\section{Research Methods}

This research uses descriptive qualitative approach. The research location is Ngada Regency, East Nusa Tenggara Province. Sources of data obtained through in-depth interviews (in-depth interviews) with parties related to poverty reduction policies in the District and study documents relevant to the research topic. Informants interviewed included resource persons from the local government component and resource persons from components outside the government. From the government component are the Regent, DPRD Chairperson, regional secretary, officials at the Ngada Regency Research and Development Planning Agency (BPLitbang) and officials on regional apparatus related to poverty alleviation programs. Regional apparatus related to poverty alleviation programs include the Social Service, the Health Service, the Education Office, the Community and Village Empowerment Office, the Women's Empowerment and Child Protection District of Ngada and the Cooperative Office, Small Businesses While the non-government components interviewed include banking representatives, cooperative representatives, representatives traditional institutions, representatives of the Catholic Church institutions, representatives of NGOs and NGOs, representatives of the business community and community representatives. Data validity is 
tested through data triangulation and data analysis using Data Condensation, Data Presentation and Conclusion Drawing.

\section{Results and Discussion}

This research confirms the application of the substantial elements of collaborative governance as stated by deSeve and examines the factors that influence or inhibit the application of collaboration in the context of poverty alleviation in Ngada Regency, East Nusa Tenggara Province. Substantial elements of collaborative governance according to deSeve include network structure, commitment to a common purpose, trust among the participants, governance, access to authority, distributive accountability/responsibility, information sharing and access to resources. While the supporting and inhibiting factors are examined from the aspect of resources, leadership, institutions and culture [9]. The results of research on the Implementation of Collaborative Governance in Poverty Reduction in Ngada Regency show the following matters:

\subsection{Network Structure}

At the local government level, the physical element of the network between stakeholders is not visible because there is no role in the organization that allows the collaboration process to proceed. The Regional Poverty Reduction Coordination Team (TKPKD), which is expected to be a forum for collaboration between stakeholders, does not play as it should. Its presence is only a formality to meet the demands of the central government and the provincial government. Linkages between stakeholders because they have the same attention as poverty issues. Meanwhile at the sectoral or program level, collaborative networks appear in collaboration with the roles of stakeholders involved in the organization of program or activity implementation. The role of stakeholders in the implementation of the program can run but always in the control and direction of the government as the owner of the program / activity. With the pattern of unequal relations between the government and components outside the government in the organization of the program implementation activities, the characteristics of collaboration are not fulfilled and still show a hierarchical relationship pattern. From the study of this network also identified the main stakeholder components that have a prominent role in poverty alleviation in the Ngada Regency, East Nusa Tenggara Province, namely the Government, Religious Institutions, Customary Institutions, Financial Institutions, especially Banking and Cooperatives, the Private World and the Community. Other stakeholder components such as Mass Media and Academics have not played a significant role in poverty alleviation in Ngada District.

\subsection{Commitment to a Common Purpose}

All stakeholders show a strong commitment to poverty alleviation efforts. Local governments have a genuine concern for the problem of poverty through vision and mission and local programs that are pro to the problem of poverty. Meanwhile other components outside the government have a specific scheme in poverty alleviation. Among the prominent ones are the Catholic Religious Institutions through the Socio-Economic Pastoral Program (PSE) as a Community Base Group empowerment program for productive endeavors, the 
Indigenous Institutions of the Bolonga Indigenous People have a local policy to reduce expenses at the moment of death, Banking and Cooperatives through financial access for micro-scale businesses and financially aware education for customers and members, NonGovernmental Organizations through the assistance of productive business groups, business world through self-help businesses and the community itself through traditional patterns of arisan and saving and participation in participatory basic infrastructure development programs.

\subsection{Trust Among the Participants}

Although not on a massive scale, there are still problems with trust among stakeholders in the implementation of poverty reduction programs. There is still a negative stigma from the government towards the involvement of other stakeholders in poverty alleviation programs. Among these are the stigma of Non-Government Organizations or Non-Government Organizations (NGOs). Local NGOs are often seen as having affiliations with local political interests, while NGOs are often seen as having a hidden mission in implementing partnership programs. There is also a negative stigma against church involvement in poverty alleviation programs. On the other hand, there are negative assessments from stakeholders outside the government on the role of the government in poverty reduction such as the content of interests for social protection programs, especially social assistance to community groups or individuals sourced from the Regional Budget Revenue and Expenditure which is thick with political interests. there is an assumption that there is a charge of interest and "favoritism" in involving partners in implementing government programs/projects.

\subsection{Governance}

In general, there has been clarity in governance in poverty alleviation programs. The most striking thing is seen in the standard poverty reduction scheme with four poverty reduction program clusters namely social protection cluster (Cluster I), community participation empowerment cluster (Kalster II), Micro and Small Business Empowerment Cluster (Cluster III) and supporting clusters that provide support for community support Divide the three main clusters (Cluster IV). Clarity of governance is also evident in the cooperation of sectoral poverty reduction activity program actors that are framed in the Guidelines or directives for the implementation of activities in the form of General Guidelines (PEDUM), Implementation Guidelines (JUKLAK), Technical Guidelines (JUKNIS) established through implementing regulations from officials authorized. With this arrangement the boundaries of who can be involved and who are not involved, clear rules of the game agreed upon together, freedom to determine how collaboration is carried out.

\subsection{Access to Authority}

The non-mediation of stakeholder meetings at a broader level causes the decision-making process to remain in the domain of the government and the interests of stakeholders cannot be communicated to the authorities to obtain feedback and solutions from the authorities in this case the government. The poverty reduction policy discussions at the district level are only limited to internal government through the Proposed Regional Apparatus Desk, the Regional Apparatus Forum, while the District Development Planning Consultation (Musrenbang) activities so far seem more ceremonial in nature but do not provide time to receive input from stakeholders in outside the government. As a result of the absence of multi-stakeholder 
meetings, the obstacles faced by stakeholders cannot be resolved, for example, the banking sector is experiencing problems related to the public's understanding of the upcoming People's Business Credit (KUR) program, the loss to the Bank without the government knowing. Application of tax regulations that do not support cooperative efforts but do not get a solution from the government. The business world has not yet received a touch of government programs to support productive businesses. Poverty alleviation policy making is still the domain of the government's role by holding regional forums and proposals for regional apparatus forums.

\subsection{Distributive Accountability/Responsibility}

The normative distribution of responsibilities between parties appears in the arrangement of the main tasks and functions in carrying out the tasks. For example, in the composition of the Regional Poverty Reduction Coordinating Team, the division of responsibilities in working groups according to the poverty reduction program has been arranged. Likewise in the implementation of programs at the sectoral level there are arrangements of tasks, responsibilities, positions and roles of each party involved in implementing the program / activity. In terms of responsiveness, each component of stakeholders has responsiveness to the problem of poverty but is still running partially there is no unity of action in the joint scheme.

\subsection{Information Sharing}

At the local government level, the process of sharing information between stakeholders has not been effective because there is no role for a representative forum to unite stakeholders in an interactive dialogue. Information sharing among stakeholders at the program level went well but was still limited to stakeholders involved in the implementation of sectoral activity programs. Each sector related to poverty reduction has an internal mechanism for sharing information but it is still in a one-way conception, namely from the government as the owner of the program to unite the understanding of the implementers of the activities. The formal mechanism of Development Planning Deliberation at each level of government (village, subdistrict and district) has not been an ideal medium for sharing information between stakeholders because it tends to be normative and regulative and tends to be seen as an internal mechanism of government. The presence of stakeholders in the mechanism does not yet reflect the collaboration process due to the strong domination by the government as the organizer of the activity.

\subsection{Access to Resources}

Stakeholder access to resources is very limited because of the control of resources by one of the stakeholders, namely the government. The government as the party playing the role of the initiator and catalyst of collaboration has not provided adequate support that opens the space for stakeholder involvement in joint poverty reduction programs. Minimal budget support for activities that involve stakeholders because the government tends to focus more on the implementation of internal government coordination.

Furthermore, the factors that provide support or obstacles to the implementation of poverty reduction collaboration include:

a) Resource Conditions

The results showed a gap in resources between the government and other components outside the government. The government has financial strength from various funding 
sources, Human Resources Support, program design and program implementation organizations. In this condition, the government tends to fall in a formalistic and regulative routine. There is also a tendency for massive program duplication between levels of government in the design of poverty alleviation programs. Here there appears to be a weakness in the creative space for local governments to adopt a more contextual poverty reduction approach. Meanwhile, other components outside the government actually have additive and contextual ways to reduce poverty that actually provide effective change to overcome poverty and create prosperity. Potential resources owned by the institutions of the Catholic Church, Customary Institutions, Cooperatives are very potential to be optimized if collaborated with the government in a joint scheme.

b) Leadership

On one hand the leader has a strong commitment to poverty alleviation efforts through the vision and mission as well as pro-birth priority programs. While on the other hand, the role of leadership in facilitating the formation of collaboration between stakeholders has not gone well. Leaders are still engaged in the environment of each stakeholder there is no unity of thought and action to form a collaborative forum. The expected role of the Government as the initiator and facilitator of collaboration between stakeholders is not yet running because it is still in the realm of internal coordination between governments and between levels of government.

c) Institutional

There are weaknesses in terms of institutional support that enables the process of collaboration between stakeholders in the true sense. The regional poverty reduction Coordination Team as a representative forum for uniting poverty reduction stakeholders exists but does not carry out its role as it should. Its presence is still formalistic to meet the demands of the central and provincial governments. For a long time Ngada Regency did not form a Regional Poverty Reduction Coordination Team. There is a simplification of this role because it is considered to be replaced by the implementation of the main tasks and functions of organic units that have the main tasks and functions of coordination of government and development in this case Bappeda and the Regional Secretariat.

d) Culture

The dominance of the government's role in the implementation of poverty alleviation programs is still strong because of the strong play "only the government can". The view that sees the government as the only party most responsible for poverty alleviation becomes a particular obstacle to inviting the involvement of other parties in joint poverty reduction schemes. Nevertheless, there has been a collective awareness within the government environment that recognizes its limitations and acknowledgment of the potential of others so that it gives birth to the need to share resources among stakeholders in poverty alleviation efforts.

\section{Conclusion}

In general, Poverty Reduction in the Regency of East Nusa Tenggara Province has not yet fully implemented the principles of Collaborative Governance as stated by deSeve. Collaboration process or dynamics in the real sense have not yet occurred in the context of overcoming poverty in Ngada Regency, what happens is patterns of relationships between parties that do not meet the characteristics of collaborative governance. Of the eight elements 
of the implementation of Collaborative Governance, Network Structure, Trust among the Participants, Access to Authority, Information sharing and Access to Resources shows a weak condition. Commitment to a Common Purpose is the most fulfilled element in its application. While the elements of Governance and Distributive Accountability/Responsibility indicate fulfillment although it is still formalistic and does not reflect the Collaborative Governance characteristics in the real sense, especially the characteristics of equality between stakeholders and consensus-based decisions.

The Conditions of Resources, Leadership, Institutions and Culture are factors that have the effect of encouraging and hindering the implementation of Collaborative Governance in overcoming poverty in Ngada Regency. The dynamics of collaboration can run optimally if supported by adequate resources, facilitative leadership, representative institutions and cultural patterns of equal stakeholder relations and no dominance of one component.

\subsection{Recommendation}

a) Collaborative management needs to be applied by the Ngada Regency government in solving public problems. There needs to be a change in the playing environment within the government to deal with public issues in togetherness rather than just relying on the government's internal capacity.

b) In the context of poverty reduction, cross-stakeholder collaboration should be an effective strategy because of the research found the extraordinary potential of each component of government and non-government so that poverty reduction becomes more comprehensive and holistic. In the context of the Ngada community, potential components outside the government that need to be optimized for their role in poverty reduction along with the government are religious institutions (Catholicism) and Customary Institutions.

c) Implementation of management needs to pay attention to the existence and ongoing collaboration that is characterized by a well-handled network, strong commitment from various parties, trust between stakeholders, clear responsive and accountable governance that allows stakeholders to access authority, information and resources.

d) The collaborative process cannot run by itself but requires systematic and schematic efforts that must be supported by adequate resources, facilitative leadership, representative institutions and a culture that is not dominating.

e) Collaborative dynamics can be managed well if the Regional Poverty Reduction Coordination Team (TKPKD) can play its role properly as a vehicle for coordination and collaboration across sectors and across stakeholders. For this reason, it is necessary to strengthen the capacity of the forum to be a place for collaboration between stakeholders, not just for coordination within the government.

\section{References}

[1] N. Henry, Public Administration and Public Affairs. New Jersey : Pearson, 2004.

[2] A. Dwiyanto, "Manajemen Pelayanan Publik: Peduli, Inklusif, dan Kolaboratif Edisi Kedua." Yogyakarta: Gadjah Mada University Press, 2011.

[3] N. Gunningham, "The new collaborative environmental governance: The localization of regulation,” J. Law Soc., vol. 36, no. 1, pp. 145-166, 2009.

[4] A. M. Bonfiglioli, Empowering the poor: Local governance for poverty reduction. United Nations Publications, 2003.

[5] G. A. Chris A, "Collaborative Governance in Theory and Practice/Ansell Chris, Alison Gash," 
J. Public Adm. Res. Theory, no. 18, p. 4, 2007.

[6] K. Emerson, T. Nabatchi, and S. Balogh, "An integrative framework for collaborative governance," J. public Adm. Res. theory, vol. 22, no. 1, pp. 1-29, 2012.

[7] Sudarmo, Elemen-elemen Collborative Leadership dan Hambatan-hambatan Bagi Pencapaian Efektivitas Collaborative Governance. .

[8] B. Hariadi, M. J. D. Sunarto, and P. Sudarmaningtyas, "Development of web-based learning application for generation Z," Int. J. Eval. Res. Educ., vol. 5, no. 1, pp. 60-68, 2016.

[9] G. E. DeSeve, "Integration and innovation," Intell. community role a netcentric Environ. Manag. networks, Soc. networks. Unlocking Power Networks Keys to High Perform. Gov. eds. S. Goldsmith DG Kettl, pp. 121-144, 2009. 